\title{
Fatal Consequences: An analysis of the failed employee voice system at the Bundaberg Hospital
}

\begin{abstract}
In this paper we discuss the failure of the employee voice system at the Bundaberg Base Hospital (BBH) in Australia. Surgeon Jayant Patel who was arrested over the deaths of patients on whom he operated when he was the Director of Surgery at the Hospital. Our interest is in the reasons the established employee voice mechanisms failed when employees attempted to bring to the attention of managers serious issues. Our data is based on an analysis of the sworn testimonies of participants who participated in two inquiries concerning these events. An analysis of the events with a particular focus on the failings of the voice system is presented. We ask the following: how and why did the voice systems in the case of the BBH fail?
\end{abstract}

Keywords: Employee voice, silence ,employee involvement, hospitals

\section{Introduction}

Surgeon Jayant Patel was arrested over the deaths of patients on whom he operated when he was the Director of Surgery at the Bundaberg Base Hospital (BBH) in Australia. What is remarkable for the practice of Human Resource Management (HRM) and the focus of this article, is not Patel's actions per se. Rather, we are interested in the reasons the well-established employee voice mechanisms in this workplace failed when employees attempted to "change rather than to escape from an objectionable state of affairs” (Hirschman, 1970: 30). 
This hospital made world news in 2005 after Patel was alleged to have caused at least 18 deaths through negligence. Medical staff making mistakes is not a new phenomena, but this was a rare case where employees attempted to voice concerns but a substantial system failure led to very public and extended legal proceedings that laid bare processes that are normally dealt with 'in house'. The remainder of this paper is as follows. Firstly, we will review some of the relevant employee voice literature. This will be followed by a discussion of our research methods. This article does not take a typical case study design but rather, our data is based on an analysis of the sworn testimonies of participants in two inquiries in to these events. An analysis of the events with a particular focus on the failings of the voice system is presented and which we represent diagrammatically before our conclusion.

\section{The effectiveness of voice systems}

The notion of increasing levels of employee voice to influence work activities and organisational decision-making is not a new. Glew, O’Leary-Kelly, Griffin and van Fleet (1995) cite Hugo Munsterberg’s Psychology and Industrial Efficiency (1913) and the Hawthorne studies from the mid-1930s (Mayo, 1933), while Kaufman (2003) cites William Basset's When the Workmen Help You Manage (1919) as examples of the interest in employee voice.Despite this long history, the literature remains bedevilled by imprecise definitions of employee voice (Dietz et al 2009, Mowbray et al 2014). The crucial defining characteristic, though, is the presence of a voiceopportunity for participants, where voice refers to "any vehicle through which an individual has increased impact on some element of the organisation... without voice, there can be no enactment of participation” (Glew et al., 1995: 402)

A voice system is that set up by the organisation to shape and channel voice (Marchington 2007) The system includes the degree, level, range and scope of issues which are within the purview of the voice system (Wilkinson et al 2013) Taking the first of these, degree indicates the extent to which employees are able to influence decisions about various aspects of management - whether they are simply informed of changes, consulted or actually make decisions. Secondly, there is the

level at which voice is expressed eg task, departmental, establishment, or corporate. The range of subject matter is the third dimension, ranging from the relatively trivial - such as canteen food 
- to more strategic concerns relating, for example, to investment strategies. Fourthly, there is the form that voice takes which could include 'on-line’ involvement (Appelbaum and Batt 1995), where workers make decisions as part of their daily job responsibilities as distinct from 'offline', where workers make suggestions through a formal scheme. This is not to say the voice system operates as designed by managers but the system describes the intent of designers of the system. A voice system has both institutional and human elements, that is both agency and structure

Much of the extant literature investigates how voice institutions are established, the motivation for them and how they are implemented. (Wilkinson et al 2014) Existing research takes a largely institutional view - that failure is the decline or collapse of the structure. However we must avoid the assumption that formalised structures resolve problems associated with providing voice (Dietz et al., 2009). A related strand of research has looked at the antithesis of voice: employee silence, defining silence as an employee's 'motivation to withhold or express ideas, information and opinions about work-related improvements’(Van Dyne et al., 2003: p.1361).

It is important to note that while schemes to facilitate voice are designed by managers the intended design and the actual scheme implemented rarely resemble each other and in this paper we can explore and explain the possible reasons for this mismatch. Glew et al note "an at-present unspecified set of organisational and individual factors may act as obstacles” (Glew et al., 1995: 397). Glew et al's approach has the merit of not restricting attention to the content of practices or to outcomes. Most importantly, it is sensitive to the perceptions, and enthusiasm and capacities of managers involved in the design and implementation of the scheme, and employees on its receiving end. So in this paper we take up Glew et al's challenge although we prefer the labels institutional and human factors as we see the term organisational as too broad while individual factors can imply a lack of agency.

Riordan et al (2005) emphasizes the importance of a supportive broader organizational context, without which isolated voice practices are likely to wither away. In our study context is very important and in particular the inherent distance between the roles and activities of professionals and those of managers. The fundamentally dialectic and negotiated nature of this relationship of 
professionals and managersat the micro level means the organizational context assumes central importance. Professional workers such as nurses are situated, make sense of, and respond to the context in which work is constructed and the opportunities and constraints presented (Cohen et al 2002).

There has been very little research to date into how employee voice systems work within a professional context let alone one where there are different professional groupings and overlaid with the increasing emphasis on managersregulating quality for the good of the organisation not necessarily the good of customers or patients. As a result, there is an inherent tension between interest groups as to what constitutes quality. But as well as managers and professionals negotiating quality thereis the issue of how professional interact given their different value systems.As Hall (2005) notes physicians aretrained to take charge, and assume a role of leadership in many settings and learning to share leadership in an interprofessional team setting is a challenge. Physicians traditionally learn independently in a highly competitive academic environment while nurses are trained to work as a team, collectively working out problems and exchanging informationacross shifts to insure appropriate continuity of care for their patients.Hall citesPetrie (1976) who suggests that each profession has a different "cognitive map" thatdevelops as a consequence of the educational andsocialization experiences of the students of each profession.Thus nurses may value thepatients' story and will not rely on objective data as heavily as do physicians (Roberts, 1989).

What is absent from the literature is a thorough understanding of what voice is heard or acted upon and following Glew et al the set of organisational and individual factors that may act as obstacles. Hence, we ask the following: how and why did the mature voice system in the case of the BBH fail? From here we are able to present a model of voice failure at an workplace level focusing on the systems and people elements of voice.

\section{Method}

These case described in the following resulted in the formation of the Queensland Public Hospitals Commission of Inquiry (QPHCI), the transcripts of which are a matter of public record. We draw on a large body of publicly-available material on the case, including, primarily, 
transcripts from the official enquiry. The strength of using transcripts rather than primary data collected from those who testified, is that the transcripts relate to views expressed under oath, which in a case carrying serious legal implications, gives the testimony a reliability that personal interviews lack. As Mellahi (2005) notes, researchers have to overcome an insurmountable hurdle to access data on senior management members' behaviour in failing organizations. Predictably, management can limit and or control access to key people, particularly if it feels it has something to hide or that research could compromise the survivability of the organization: indeed gaining access on corporate governance problems has been described as 'one of the most challenging barriers researchers face' (Daily et al. 2003). Given such problems, the Bundaberg case offers a unique opportunity to investigate the dynamics of failure and the related failure of voice. Case study literature suggest that critical incidents and extreme cases offer more to researchers than representative cases (Eisenhardt 1989) and using documents in research to explore organisations has been underutilised (Lee 2012). It is a methodology which is becoming increasingly utilized in the area (see for examples, Mellahi 2005).

The Queensland Public Hospitals Commission of Inquiry (QPHCI) arose out of complaints relating to Dr Jayant Patel at BBH in 2004 and early 2005. These complaints, and other concerns expressed about Dr Patel's judgment, competence and care, and the failure of BBH's administrators and later officers of Queensland Health $(\mathrm{QH})$, to address those complaints and concerns were one of the main focuses of the Inquiry. Hence, the transcripts contained detailed information about the number of complaints and conduits, informal or formal, through which they were made. In addition to Inquiry transcripts, we also used the report from an independent review on the events established by the Queensland Government and commonly referred to as 'The Forster Report'."E" numbers in our paper refer to exhibits that were largely testimonies and interviews that occurred before the inquiry. "T" numbers are transcripts from the inquiry itself.This Commission sat for a total of 30 days hearing evidence from a 37 witnesses and receiving a little over 200 further exhibits. As such, we initially drew our sample to dismiss those witness statements that were not directly related to systems of employee voice, for example, from patients and their families. Twenty witness statements from key witnesses who had given evidence relative to Dr Patel and the Bundaberg Hospital were reviewed for this paper. These witnesses were Michael Allsopp, Dr Pitre Anderson, Gail Aylmer, Dr Dieter Berens, Dr Steven 
Buckland, Dr Peter Cook, Lindsay Druce, Dr Gerard Fitzgerald, Toni Hoffman, Michelle Hunter, Dr Christopher Jeliffe, Dr Jason Jenkins, Dr Jonathan Joiner, Dr Darren Keating, Peter Leck, Rob Messenger MP, Dr Peter Miach, Robyn Pollock, Dr David Smalberger and Dr Brian Thiele. The transcripts were examined for evidence of the extent to which voice mechanisms were used to lodge complaints regarding Dr Patel, and why staff members chose to use (or avoid) a particular mechanism. In reading each transcript, we searched initially for text which represented the use of a voice mechanism. This was then assigned a code, and characteristics of the complaint were tabulated. These characteristics included: who raised the complaint, what the issue was, after what sort of incident and why, to whom it was reported, the voice mechanism used and the outcome. The transcript page was noted, and the date where available. Incidents were recorded in the table in chronological order.The availability of different sources of information allowed the triangulation of data in order to increase the reliability of the findings.

The resulting dataset was then examined to ascertain major themes regarding the failure of the complaints system. It was important for the researchers to have a common understanding of the categories within the voice framework and to establish inter-rater reliability (Meadows and Morse 2001). To achieve this, the authors drew a sample of each witness statement to code independently and then met to discuss the consistency of coding. There was near complete agreement over the interpretation of the coding, and on the few points where there were differences these points were discussed and disagreement resolved.

\section{Bundaberg Base Hospital}

$\mathrm{BBH}$ is located in the coastal town of Bundaberg, in the state of Queensland, Australia, and serves a catchment of around 85000 people. When the events occurred, the hospital had almost 150 beds, approximately 850 employees, including 65 medical practitioners and an annual budget of around 56 million dollars (Forster, 2005). The BBH during the period of 2004-2005 had 18,000 admissions, 24,500 outpatient's visits and 28,500 emergency treatments (Forster, 2005). It is part of Queensland Health, the government health provider, which employs approximately 53,300 employees including approximately 45,000 full-time staff. Due to its regional nature, $\mathrm{BBH}$ has difficulty attracting (in particular) senior staff and faces more severe 
labour shortages than hospitals in major cities or towns. Subsequently, it must refer complex operations to Brisbane, the state’s capital city (Davies, 2005).

According to the Davies Report (2005) these factors contributed to the events at the BBH. Doctors were working long hours that could have constituted unsafe standards and surgeons at the hospital complained of understaffing and low morale. Several surgeons and doctors employed at the $\mathrm{BBH}$ made it clear that there needed to be systemic improvements at the hospital and more staff especially doctors and nurses were desperately required (E199). During late 2002 and early 2003, a number of surgeons at the BBH left QH because they felt frustrated that they were ignored about resource problems (Forster, 2005).

Like many hospitals Queensland Health overall utilizes an array of voice mechanisms, including incident reports and the complaint management system (Davies, 2005). In addition, grievance procedures allow staff to complain about issues affecting them. But these procedures can be time consuming due to the hierarchical organisation and it can take a considerable time for these complaints to be acted upon (see Florens 2006). Furthermore, it is evident that the system did not operate coherently with some mechanisms overlapping with each other causing confusion for employees when attempting to use them (Forster, 2005). Perhaps most critically, according to an experienced director of medicine, BBH had a history of a culture of 'pleasing the boss' where complaints were often not forwarded or were reworded to appear less negative (Thiele, E118). This was the context for the appointment of Dr Patel who began work at the BBH in April 2003 as Director of Surgery.

\section{Rumblingvoices ignored}

Within two months of Dr Patel's arrival complaints from staff began. One patient was given an incorrect procedure (Davies, 2005) and another complaint related to a complex procedure that should not have been performed at BBH that left the patient in critical condition. These brought Dr Patel to the attention of Toni Hoffman, a senior nurse in the intensive care unit who became the eventual whistle blower (Davies, 2005). After the patient died, Ms Hoffman approached the Director of Nursing to have a meeting about the incident, a meeting which involved Dr Patel and the Dr Keating the Director of Medical Services (E4). Dr Patel then explained the circumstances 
surrounding these issues (E471) and Hoffman as a nurse had no option but to accept Dr Patel's explanations despite her discomfort with what had occurred.

During his time at $\mathrm{BBH}$, no fewer than 20 complaints were made against Dr Patel, relating to incompetence, unnecessary surgery, performing surgery above his skills, and hygiene concerns (Forster, 2005) but these complaints were not acted upon by management (E133, E128 and E21). Dr Miach went so far as instructing several of the doctors and nurses at the hospital that Dr Patel was not to operate on his patients (E21). Despite this, during the majority of Dr Patel's two-year term no complaints broke through the hierarchy beyond the level of Dr Keating the Director of Medical Services and Mr Leck the Hospital District Manager (E473). Complaints were often downplayed and/or ignored and none of these complaints were acted upon. In fact, Dr Patel won employee of the month during November of 2004 and his contract was to be extended in January 2005. Clearly, the system of employee voice was failing.

Nurse Hoffman had increasing concerns with developments and the actions of Patel. She tried internal avenues including a meeting with the Director of Nursing and writing a detailed complaint. However, nothing eventuated for several months and Ms Hoffman then decided to approach the local Member of Parliament (MP). Mr Rob Messenger in his role as MP, made enquiries about the Patel situation and when he was convinced of the seriousness of the events raised the issue in parliament.

Even after this dramatic action, QH Managers sought to downplay the events occurring at the BBH in relation to Dr Patel. Active — and largely standard — crisis control measures were put into place. Communication by staff at the hospital to outside sources was discouraged by senior QH Management (see E4 and E70). Dr Patel continued to practice and it was not until the $29^{\text {th }}$ of March that he was stopped from practicing and he left Australia two days later.

On the $23^{\text {rd }}$ of March, Mr Messenger addressed the Queensland State Parliament. Hospital management also met with nurses from the intensive care unit (E473). At this meeting staff members were told of their obligations under the QH Code of Conduct and that speaking to outside sources could have serious ramifications on their job security. The nurses were also 
discouraged from making any further contact with non-QH sources. However, the leakage of information continued, and, on the $13^{\text {th }}$ of April 2005 a story in Queensland's sole daily newspaper, the Courier Mail triggered widespread interest and a commission of inquiry was

announced on the $26^{\text {th }}$ April. This commission happened some 23 months after the first complaint was made against Patel in the workplace (Davies, 2005).

\section{The Failure of voice: Why?}

BBH appeared to have adequate opportunities for employees to voice. There were multiple, wellestablished voice channels and staff were professionally trained and motivated. The matters being dealt with could not be more serious but the messages that were transmitted through the voice system appeared not to be taken seriously or given priority. When we examine the sworn testimony we can categorise the factors into two streams - those which are human elements and those which are institutional elements. These correspond to Glew et al comment that "an atpresent unspecified set of organisational and individual factors may act as obstacles ... (to voice )" (Glew et al., 1995: 397). The following sections of this paper provide an analysis of these problems in turn, starting with the human elements.

\section{Complex networks}

This case illustrates the complexity of voice in the context of professional groupings where some voices are more equal than others. Those managers with a more administrative role (e.g. Keating and Mulligan) were very removed from the 'clinicians'. Keating was more focused on budgets and Mulligan, Hoffman believed, was not as 'hands on' as previous line managers in that role. More generally, management was focused on minutiae, and the voice mechanisms were not systematised to the degree that encouraged big picture clarity. From the perspective of a wellfunded inquiry, Patel's (alleged) incompetence was clearer, but in the 'fog of war' that is the day-to-day functioning of a hospital, the mere presence of voice mechanisms, and even the active use of these mechanisms, did not mean that a single, simple picture emerged on which management could act as information was fragmented. 
The personnel combination was crucial - in this set of circumstances we have a medicallyqualified administrative member of staff (Keating) who was not active in pursuing complaints, and the next line of management (the non-clinically-qualified Leck) having the power to make a judgement but lacking the insight or skill in a clinical area, and hence dependent on the recommendation of their subordinate (Keating) (T7131). To compound this problem, there were complaints from staff regarding accessibility to management. For example, Dr Miach spoke about wanting to raise issues with Keating, and that he approached Keating with the idea that they could sit down regularly, once a fortnight or once a month to discuss concerns but Keating was 'not interested'. Miach goes on further to say 'he was astounded that ... my approach to try and improve things in the hospital as far as medicine was ... turned down point-blank' (T300). At one point in his testimony, he paraphrases his attitude: 'what's the point of doing anything' (T301). This view is similar to that found in the Nielsen et al. (2008) research where employees faced the 'learned helplessness’ after repeated failure to express voice.

\section{Hierarchy disrupts voice}

There is a long-established literature that explains that managers typically have control over what voice mechanisms are used, heard, and acted upon (Marchington et al, 2001). From the testimony it is clear that it was harder for a nurse to exercise voice by completing an adverse event form suggesting fault with a doctor's clinical judgement; far easier to complete a form for a faulty piece of equipment; Nurse Hoffman states people were frightened that they would get into trouble (T1367).

Nurses very rarely commented independently on the clinical competence of a doctor without the consent or support of others (T1378). The professional pecking order was clear and not to be breached and this meant voice could not flow into channels in the manner those who created the voice mechanisms might have imagined. Although Dr Keating states that he did not 'consider nurses were somehow inferior to doctors' (T6978), Hoffman believed the reality was quite different. Dr Patel's attitude was perhaps more reflective of reality: he allegedly made disparaging remarks about nurses. Certainly the perception that when it came to raising concerns, management believed doctors more than nurses was not uncommon. 
An example of this is when Nurse Hoffman pointed out her concern about Patel's choice of practices did not reflect best practice guidelines in Australia. Dr Keating's response to the Inquiry about this complaint was he was not made aware of the situation from an anaesthetist, and if such a problem existed, he believed they would have brought it to his attention (T6834). This meant that in practice only certain voices were to be given credence with others to be discarded or discounted. We can see this again when Nurse Aylmer complained to Keating that Patel was not following infection control measures. Aylmer's feedback from Keating was that he had spoken to Patel who had a different version of events compared to the nurses. Again, Aylmer had the impression that Keating preferred Dr Patel's version over the nurses (T988). Alymer stated 'I just wondered how many nurses it would take to be believed over the top of Dr Patel ...' (T988). Dr Keating showed insensitivity to the layered professional nature of hospital hierarchy. When he was made aware by nursing staff that Dr Patel was yelling at staff, for example, he investigated the complaint by speaking to a doctor, who reported that he had not felt intimidated (T6838).

Other evidence of a clear division between the doctors and nurses, and the differential weighting of their voices, can be seen in reports of a staff meeting where management told staff there would be a terrible rift between the doctors and the nurses in ICU over the Patel issue. A staff member said the message she got from the meeting was 'look at what these nurses have done; made a mess for Bundaberg; got rid of this brilliant surgeon' (T1009). She goes on further to say this made nurses feel less discouraged to stand up and be heard (T1009).

\section{Informal versus formal voice}

The interplay between informal and formal voice is a mist of human and instuional elements (Townsend et al, 2013; Marchington and Suter, 2013). It is clear from the evidence presented to the Inquiry that complaints were made, either via email, in meetings or in person. Formal channels were not used because of time pressures that lead to a culture of dealing with issues as they arose, or not at all (T1363); the sense that the staff felt they had met their ethical obligations and passed on information to their direct line manager; concern about repercussions and being 
unaware of the correct procedures to follow. There is also evidence that the view had been implicitly or explicitly transmitted to staff that the use of formal voice was frowned upon.

At a seminar held by the Ethical Standards Branch of QH, employees were told it was illegal to speak to the union about hospital-related business (T170-1) and that 'there's really nowhere to go' (T1028). Staff were given copies of the Code of Conduct for QH and an industrial relations manual about what happens to whistleblowers (T185). The manual shows staff could go to jail for releasing information to an unauthorised person (T185). This was clearly not a positive context for voice to flourish. As Detert and Burris (2007) note employees learn to interpret both spoken and unspoken restraint on voice.

Initially, Hoffman didn't want to lodge a formal complaint. She wanted to let management know of the issues, and she simply wanted someone to look into her concerns to see if something was wrong (T1378). As a colleague of Patel's however, she also needed to maintain the working relationship. Formally expressing voice about an identified colleague clearly suppresses willingness to speak.

There were various formal meetings held where employees could have voiced complaints. One of these was the ASPIC (Anaesthetic Surgical Pre-Admission and Intensive Care Staff) Clinical Forum. Hoffman spoke about not using the ASPIC Clinical Forum as an avenue to complain, because she felt she had already spoken (informal voice) to key people present at the meeting about the problems, and also she did not feel it was appropriate to bring something like that up at a meeting in front of other people who may not have had anything to do with the issues surrounding Patel (T1387).

Hoffman stated if she brought things up in ward-level nurse meetings, her line manager (Mulligan) as chair would say 'this is not the place to discuss it', and when Hoffman would try to make an appointment with Mulligan she could not get in to see her (T125). Hoffman felt the nurse meetings were not the venue for open conversation anyway. She felt something less structured where people felt comfortable speaking out would have been better (T1353). 
Formal meetings were held to look at adverse events that had occurred. One of the nurses that attended these meetings said Patel would say he would take it back to a meeting with the doctors and discuss it with them (T2038-9). These meetings were supposed to occur monthly, but did not (T2039). The irregularity of the meetings was partially related to Dr Patel being unavailable, as well as the complications of shift work and co-ordinating times. Patel was a member of the review committee where he would have to question his own competence. Keating admitted this was a problem with the system (T6961).

\section{Opaque, passive systems}

A number of staff were not aware of the correct procedure for expressing formal voice. For example, if we take the case of Dr Smalberger who received an orientation hand out aimed at clinical work and clinical procedures, but could not recall receiving anything on procedures for laying complaints (T1984). He raised his concerns about Dr Patel verbally with management, and asked what the correct procedure should be, but he states he was never told the procedure, nor had any formal feedback after his discussion with management (T1974; E133). Dr Keating said he did not receive any booklets or procedure manuals from the hospital when he commenced in the position, although he did become aware at a later date of some policies on the hospital's intranet (T6932-3).

Dr Beren stated in his testimony that he was not aware of his options externally (T1945). It was also noted in testimony that staff were discouraged to go outside the system, and that 'the

discouragement is more obvious to some people than others and it depends on the seniority and what ... they do' (T350). Dr Beren at a relatively early stage aired his concerns over the death of a patient and felt that it should have been referred to the coroner. He did not file a written complaint, but argued that if management wanted him to write a written complaint he would have done so (T1943). Clearly, in addition to the mere presence of voice mechanisms, in high stakes cases such as this, staff were looking for more than passive availability of voice mechanisms, but clear active encouragement of their use. At the same time staff either felt they could not use the formal voice channels as management had not given their blessing to do so. When Keating was questioned about why, after three doctors had corroborated the views of Nurse Hoffman, there was no recommendation for Patel to refrain from surgical services, 
Keating's response included that there were no processes dictating how to truly investigate the allegations made by Hoffman in this situation within QH (T6864).

\section{External pressures: No hospital is an island}

It is well established within workplace studies that the external environment and context can

have a significant influence on what occurs within the organisation. Management was clearly disinclined to pursue complaints voiced due to the potential impact on funding and publicity. Government bureaucracies operate under formal codes of confidentiality and conduct, and Queensland Health was no exception. Mr Leckstates that adverse publicity was frowned upon and that going to the press was in breach of the Code of Conduct (T7130). Dr Keating stated Leck was focused on making sure the information was not spread far and wide across the organisation (T6841) and keeping control of leakages (T6848). Patel was economically valuable to the executive and there appeared to be a culture of focusing on quantity (number of particular procedures that had taken place) not quality (clinical outcomes) (T7010-13) a problem that has been noted elsewhere (West et al. 2006).

This appears to be a inherent tensions with managing medical systems with performance-related rewards and punishments. Dr Cook states he believes there was a conflict of interest that the same people who regulate the standards of QH Hospitals are also penalised in a budgetary sense if sufficient surgery is not achieved (E218). Aylmer states 'staff overall had a feeling that there was no point in saying anything ... [Dr Patel] would go around saying that ... he was protected by the executive, that he was making all this money for them ... but the thing was the impact that had on people was, “what's the point?” '(T999A).

\section{Overall voice system performance}

It is clear that line managers are critical gatekeepers for voice both (Townsend et al 2013)in that they can facilitate voice, but are equally able to stifle it, passively or actively. The testimony of staff spoke about the perception that Keating was too busy for their complaints, with other aspects of hospital practice taking priority. While he did allow staff to voice their views he also gave the impression they were wasting his time. Miach explains that Keating's mannerisms in 
meetings made it quite clear that he (Keating) was not interested (T301). Aylmer states she was made to feel a troublemaker: 'if you aren’t going to deliver me good news, I don't want to know any news'. She felt that she was being judged for bringing things up that may be regarded as emotive (T999).

As a manager, Keating tended not to follow up complaints and gave no feedback to the complainant. For example, he would speak to another staff member to see if they had the same experienced and if they had not, the complaint was disregarded, and the original complainant was not told of the discrepancy. At times, despite his own role and power, Keating would expect the complainant themselves to deal with the issue, apparently oblivious to the difficulties posed by the power differential between the parties. This is most evident where it was suggested to Hoffman that she raise her concerns with Patel himself. Keating seemed to take the view that as professionals, co-workers could and should be able to sort things out themselves. An example of this is a report Aylmer presented to Keating about the increase in wound dehiscence. The approach Keating took was to pass the report directly onto Patel who then confronted Alymer. Alymer stated she did not think it was her role to review a surgeon's expertise, and beyond her scope of practice to be arguing or debating this with a surgeon (T976). Patel stated his accomplishments and his experience and Alymer reported feeling intimidated and out of her depth (T977). Once again, Keating’s viewpoint was that Alymer was a senior clinician and she should speak to the other clinicians involved (T6985). The implication was that while 'senior' (i.e. clinician's) voices were favoured in the complaints process, when it came to resolving complaints, Keating regarded all voices as equal.

Most of the nursing staff discussed in their testimony the lack of feedback and the resulting impression that their voice was not being valued. This also related to adverse event forms. According to Miach (T343) 'Forms, in fact, they were filled in, they went somewhere and who knows where they went ... I never received any feedback on adverse events.'

There were various reasons given for why complaints were not followed up. More information was asked for and not received (T7004); the staff member didn’t want any action taken (T7217); aware that postoperative complications could occur (T6983); if a doctor had a problem they 
would have brought it to their attention as well (T6834); someone else was in control of the situation and they were just doing tasks relating to the investigation of the complaint (T6835). The evidence presented is clear. There were multiple channels of voice available(c.f. Pyman et al, 2006). However, a combination of human elements and system elements led to a catastrophic failure of the system at $\mathrm{BBH}$.

\section{Voice system failure}

Evidence given under oath offers unusual insight into constraint in a circumstance where voice failure lead to severe consequences even in an environment when multiple channels of voice are present and, on the surface, supported. Hospitals perhaps more that most organisations have formal reporting requirements running parallel to the various formal and informal channels of voice. Medical staff are linked to the patient in a formal relationship with legal and ethical bonds. From here, we can develop a simple mapof employee voice failure (presented in Figure 1).

\section{[INSERT FIGURE 1 ABOUT HERE]}

A number of key themes that emerge from the testimony have broader applicability to our understanding of voice. Voice is the product of agency and structure. In the BBH case, the human factors include the complex personal networks; professional conflicts; and the gap between formal and informal voice. Instiuonal factors also include the interplay between informal and formal voice, but also contain the presence of opaque, passive systems; and the recognition of the pressing external environment. Combined, these five elements of the voice system explain the system failures.

Blockage of voice was a result of the nature of the modern hospital, where specialisation is increasingly the pattern (Capkun, Messner and Rissbacher, 2012). In bureaucratised systems, demarcations may become a justification for institutionalised apathy. Parties may be actively encouraged to avoid intruding into the jurisdiction of others. It is difficult to ensure the integration of the different voices that emerge from different professional perspectives (Gittell, 
2009). In recent years, there have been clear external pressures for hospitals, particularly in the area of funding. The active voice of the nurse or doctor takes place against a background of institutional noise that makes it likely that much voice is not heard, rather than deliberately repressed. Clearly the presence of voice channels does not guarantee employees will use the mechanisms, or indeed that the right managers will hear the voices, and act on what they hear (c.f. Wilkinson et al, 2013, 2014 ; Pyman et al, 2006). Managers heard employee voice informally, but under time and resource pressures and sensitive to issues of power and professional expertise they either discounted them or set the bar so high that single voices were ignored unless there was corroborating data. Managers then never sought to get such data.

It appears that managers were often not properly trained in creating, operating and upgrading employee voice systems (Forster, 2005). Indeed part of their proscribed role was to ensure negative information was not communicated to outside bodies (Davies 2005). While confidentiality is a key element of ethical behaviour within medical organisations, it is easy for a prohibition of one kind of voice to be read as a prohibition on all. This case also illustrates the importance of active listening to complaints as part of the voice system. It illustrates how stifled voice can rapidly create a sense of learned helplessness. Past failures of voice systems to work lead employees to believe that these systems did not function effectively (Florens, 2006). So, voice structures that are not used seem to atrophy and lose legitimacy (Wilkinson et al, 2013). This is a different view of employee silence than that that exists in much of the literature, where it is viewed as something of a freely undertaken choice. Morrison and Milliken (2000), however, have sought to explain why silence is systemic in many workplaces, and the kinds of norms and forces that set it in process and reinforce it. Principally, they identify the role of top management as having a role in stimulating or suppressing voice. In environments where negative feedback is critical to addressing safety-such as hospitals—it is important to create a climate where employees feel comfortable about raising problems, Management have the power to encourage or impede effective voice-formal and informal —and it is clear from the BBH case that even mature and elaborate formal and informal voice mechanisms/opportunities will not gurantee accurate transmission of voice. Many voice systems encounter 'deaf ears' and frustration can be evident (Harlos, 2001). 


\section{Acknowledgements}

To be included post review.

Note: In 2010, Patel was sentenced to seven years imprisonment for manslaughter. In August 2012, his convictions were quashed by Australian high court and a retrial ordered due to 'highly emotive and prejudicial evidence that was irrelevant to the case'.

\section{Autobiographical note}




\section{References}

Appelbaum, E. and Batt, R. (1995) Worker Participation in Diverse Settings: Does the Form Affect the Outcome, and, if so, Who Benefits?, British Journal of Industrial Relations, 33(3), 353-78.

Barry $\mathrm{M}$ and A.Wilkinson

Capkun, Vedran, Messner, Martin, \&Rissbacher, Clemens.(2012). Service specialization and operational performance in hospitals.International Journal of Operations \& Production Management, 32(4), 468-495.

Daily, C. M., Dalton, D. R. andCannella Jr., A. A. (2003) Corporate Governance: Decades of Dialogue and Data, Academy of Management Review, 28 (3) pp. 371-382.

Cox, A., Zagelmeyer, S. and Marchington, M. (2006) Embedding employee involvement and participation at work, Human Resource Management Journal, 16 (3) 250-267.

Daily, C.M. Dalton, D.R.,Cannella Jr., A.A. (2003) Corporate Governance: Decades of Dialogue and Data,Academy of Management Review, 28 (3): pp. 371-382.

Davies, G. (2005) Queensland Public Hospitals Commission of Inquiry Report. www.qphci.qld.gov.au, accessed $25^{\text {th }}$ June 2006.

Detert, J., and Burris, E. (2007) Leadership Behaviour and Employee Voice: is the door Really Open? Academy of Management Journal, 50(4): 869-884.

Dietz, G., and Redman, T. (2009) Employee voice and participation in The Sage Handbook of Human Resource Management. London: Sage.

Dutton, J., Ashford, S., O-Neill, R and Lawrence, K. (2001) Moves that Matter: Issue Selling and Organisational Change, Academy of Management Journal, 44, 716-736.

Eisenhardt, K.M. (1989), “Building theories from case study research”, Academy of ManagementReview, 14 (4), pp. 532-50.

Florens, P. (2006) Why Won't Anyone Listen? Employee Voice at the Bundaberg Hospital Fiasco, Unpublished Honours Thesis, Department of Employment Relations, Griffith University, Brisbane.

Forster, P. (2005). Queensland Health Systems Review: Forster Report. www.healthreview.com.au, accessed June $30^{\text {th }} 2006$. 
Gittell, J.H. (2009). High Performance Healthcare: Using the Power of Relationships to Achieve Quality, Efficiency and Resilience. New York: McGraw-Hill

Glew, D.J., O’Leary-Kelly, A.M., Griffin, R.W \& van Fleet, D.D (1995). 'Participation in organizations: a preview of the issues and proposed framework for future analysis', Journal of Management, 21 (3), 395-421

Hall P (2005) Interprofessional teamwork: Professional cultures as barriers Journal of Interprofessional Care Vol. 19, No. s1, Pages 188-196

Hamel-Lauzon, Gloria, \&Lauzon, Sylvie. (2013). Nurses’ Failure to Report Elder Abuse in Long-Term Care: An Exploratory Study. (Re)Thinking Violence in Health Care Settings: A Critical Approach, 107.

Harlos, K. (2001) When Organizational Voice Systems Fail: More on the Deaf-Ear Syndrome and Frustration Effects, The Journal of Applied Behavioural Science, 31 (3) 324-342.

Hirschman, A. (1970) Exit, Voice and Loyalty: Responses to Decline in Firms, Organizations and States, Cambridge: Harvard University Press.

Kaufman, B (2003). 'High-level employee involvement at Delta Air Lines'.Human Resource Management, 42 (2), 175-190

Lee, B. (2012)Using documents in organisation research in Symon G and C.Cassell,Qualitative Organizational Research, Sage.

Marchington, M, Wilkinson, A, Ackers, P and Dundon, T (2001). Management Choice and Employee Voice, London, CIPD

Marchington, M. (2008) Employee voice systems, The Oxford Handbook of Human Resource Management, Oxford: Oxford University Press.

Mayo, E (1933). 'The Human Problems of an Industrial Civilization'. New York

Meadows, L. M., \& Morse, J. M. (2001).Constructing evidence within the qualitative project. The nature of qualitative evidence, 187-200.

Mellahi, K. (2005), 'The Dynamics of Boards of Directors in Failing Organizations', Long Range Planning, 38, pp. 261-279

Milliken, F.J., Morrison, E.W. and Hewlin, P.F. (2003) An exploratory study of employee silence: issues that employees don't communicate upward and why, Journal of Management Studies, 40(6) 1453-1476.

Mowbray P, Wilkinson A and H.Tse (2014) An Integrative Review of Employee Voice: 
Identifying a Common Conceptualization and Research Agenda International Journal of Management Reviews

Morrison, E \& Milliken, F. (2000). Organizational Silence: a Barrier to Change and

Development in a Pluralistic World, Academy of Management Journal,42, 403-419.

Piderit, S.K. and Ashford, S.J. (2003) 'Breaking silence: tactical choices women managers make in speaking up about gender-equity issues', Journal of Management Studies, 40(6): 14771502.

Pinder, C. C., \&Harlos, K. P. (2001). Employee silence: quiescence and acquiescence as responses to perceived injustice. Research in personnel and human resources management, 20, 331-369.

Pyman, A., Cooper, B., Teicher, J., Holland, P.J., 2006, A comparison of the effectiveness of employee voice arrangements in Australia, Industrial Relations Journal, vol 37, issue 5, Blackwell Publishing Ltd, Oxford UK, pp. 543-559.

Riordan, C.M., Vandenberg, R.J \& Richardson, H.A (2005). 'Employee involvement climate and organisational effectiveness'.Human Resource Management, 44 (4), 471-488.

Roberts CS (1989) Conflicting professional valuesain social work and medicine Health and Social Work August 211-218.

Strauss G (2006) Worker participation: Some under-considered issues.Industrial Relations 45: 778-803.

Townsend, K., Wilkinson, A., and Burgess, J., (2013) 'Filling the Gaps: Patterns of Formal and Informal Participation' Economic and Industrial Democracy, Forthcoming.

Van Dyne, L., Ang, S. and Botero, I.C. (2003) Conceptualizing employee silence and employee voice as multi-dimensional constructs, Journal of Management Studies, 40(6) 1359-1392

West M, Guthrie J, Dawson J, et al. (2006) Reducing patient mortality in hospitals: The role of human resource management. Journal of Organisational Behaviour, 27: 983-1002.

Wilkinson, A., T. Dundon and M. Marchington (2013 a)Employee Involvement and Voice in S. Bach and M. Edwards (eds), Managing Human Resources, 5th edition, Oxford: Blackwell, pp. 268-288.

Wilkinson, A., Townsend, K., \& Burgess, J. (2013b ). Reassessing employee involvement and participation: Atrophy, reinvigoration and patchwork in Australian workplaces. Journal of Industrial Relations, 55(4), 583-600. 
Wilkinson, A., \& Fay, C. (2011).New times for employee voice? Human Resource Management, 50(1), 65-74.

Wilkinson, A., Donaghey, J., Dundon, T. and Freeman, R. (2014). 'Employee voice: Charting new terrain'. In Wilkinson, A., Donaghey, J., Dundon, T. and Freeman, R. (eds), The Handbook of Research on Employee Voice. Cheltenham: Elgar Press, pp 3-16. 
Figure 1: Elements of Voice Failure

\begin{tabular}{|c|c|c|c|}
\hline \multirow{5}{*}{ Voice System Failure } & \multirow{3}{*}{ Human Elements } & Complex Networks & \multirow{5}{*}{ 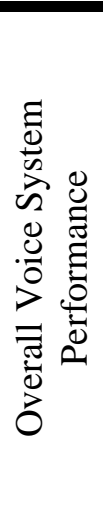 } \\
\hline & & Professional Conflict & \\
\hline & & Informal v Formal Voice & \\
\hline & \multirow[t]{2}{*}{ Institutional Elements } & Opaque, Passive Systems & \\
\hline & & External pressures & \\
\hline
\end{tabular}

